\section{UJMM

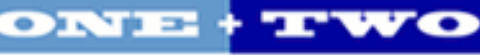

Volume 3 | 2011 Spring

\section{Undergraduate Journal of Mathematical}

Modeling: One + Two

\title{
Blood Alcohol Content
}

Chris Ludwin

University of South Florida

Advisors:

Brian Curtin, Mathematics and Statistics

Scott Campbell, Chemical \& Biomedical Engineering

Problem Suggested By: Scott Campbell

Follow this and additional works at: https://digitalcommons.usf.edu/ujmm

Part of the Mathematics Commons

UJMM is an open access journal, free to authors and readers, and relies on your support:

Donate Now

\section{Recommended Citation}

Ludwin, Chris (2011) "Blood Alcohol Content," Undergraduate Journal of Mathematical Modeling: One + Two: Vol. 3: Iss. 2, Article 1.

DOI: http://dx.doi.org/10.5038/2326-3652.3.2.1

Available at: https://digitalcommons.usf.edu/ujmm/vol3/iss2/1 


\title{
Blood Alcohol Content
}

\begin{abstract}
Given a set of differential equations describing blood alcohol content as a function time, we integrated the equations to obtain a general solution. The general solution equation depends on three free parameters: the initial concentration of alcohol in the stomach after ingestion, the rate of alcohol absorption into the blood stream and the rate at which the alcohol is metabolized by the liver. We fitted our solution to experimental data to determine the unknown parameters for a particular subject.
\end{abstract}

\section{Keywords}

Chemical Rate Laws, Differential Equations, Curve Fitting

\section{Creative Commons License}

\section{(c) (1) $9 \odot$}

This work is licensed under a Creative Commons Attribution-Noncommercial-Share Alike 4.0 License. 


\section{TABLE OF CONTENTS}

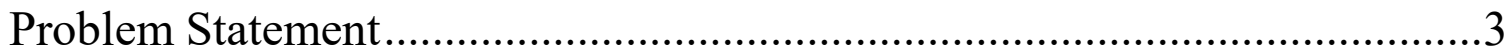

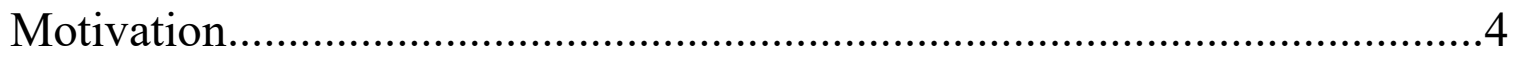

Mathematical Description and Solution Approach .....................................4

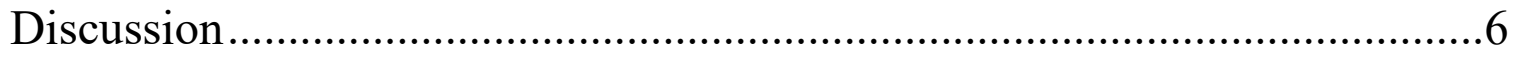

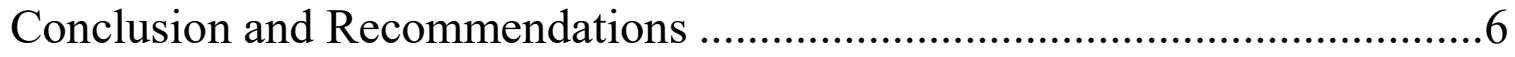

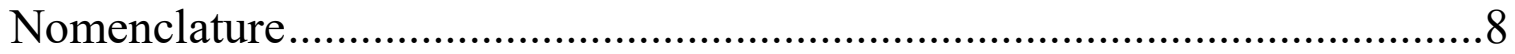

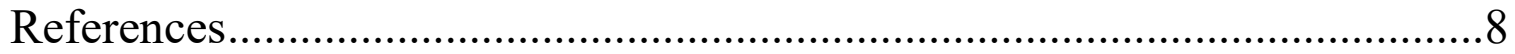




\section{PROBLEM STATEMENT}

It is proposed to model the processing of ethanol in the human body by the following reaction scheme:

$$
A \Rightarrow B \Rightarrow C
$$

where $A$ represents the concentration of alcohol in the stomach, $B$ represents the concentration of alcohol in the blood and $C$ represents the concentration of byproducts in the blood after the alcohol is metabolized by the liver. Along with the above reaction scheme, it is proposed that the kinetics of the reaction steps are first order so that,

$$
\frac{d A}{d t}=-k_{1} A
$$

and,

$$
\frac{d B}{d t}=k_{1} A-k_{2} B
$$

\begin{tabular}{|cc|}
\hline $\begin{array}{c}\text { Time } \\
\text { (minutes })\end{array}$ & $\begin{array}{c}\text { Blood Alcohol Level } \\
(\mathrm{mg} / \mathrm{L})\end{array}$ \\
\hline $\mathbf{0}$ & 0 \\
\hline $\mathbf{1 0}$ & 150 \\
\hline $\mathbf{2 0}$ & 200 \\
\hline $\mathbf{3 0}$ & 160 \\
\hline $\mathbf{4 5}$ & 130 \\
\hline $\mathbf{8 0}$ & 70 \\
\hline $\mathbf{9 0}$ & 60 \\
\hline $\mathbf{1 1 0}$ & 40 \\
\hline $\mathbf{1 7 0}$ & 20 \\
\hline
\end{tabular}

where $A$ and $B$ represent the concentrations of species $A$ and $B$.

Table 1: Blood alcohol level for a $75 \mathrm{~kg}$ subject after drinking $15 \mathrm{mls}$ of $95 \%$ alcohol

Given the initial conditions $A(0)=A_{0}$ and $B(0)=0$ along with the experimental data in Table 1, determine the function $B(t)$. 


\section{MOTIVATION}

Knowing the concentration of a given reactant in a reaction system is quite useful, especially if you are able to accurately model the concentration as a function of time. The ability to do this is an extremely useful technique not only for modeling the chemical reactions themselves, but also for designing reaction systems, and deciding on equipment parameters. For example, this proposed method of modeling blood alcohol data can be potentially useful to companies planning to manufacture breathalyzing equipment.

Of course, the ability to model blood alcohol content as a function of time is an attractive concept to medical personnel as well. Besides modeling the blood concentration for the sole information, the techniques could perhaps be used to compare the metabolic ability of a given subject's liver to that which would be considered normal. It is also quite probable that the methods used here could be applied towards modeling the concentration and metabolism of other endogenous compounds, such a blood glucose levels, or an administered medication. Examples like these illustrate why chemical rate laws are so powerful for keeping track of and optimizing reactions, and have high applicability towards modeling real situations.

\section{MATHEMATICAL DESCRIPTION AND SOLUTION APPROACH}

In order to determine the blood alcohol level $B(t)$ explicitly we must first solve the differential equations (2) and (3). After we separate the variables in (2) we have,

$$
\frac{d A}{d t}=-k_{1} A
$$

thus we integrate and use the given initial condition, $A(0)=A_{0}$, to obtain,

$$
\ln (A)=-k_{1} t+C=-k_{1} t+\ln \left(A_{0}\right)
$$


It is more convenient to express equation (5) as:

$$
A=A_{0} e^{-k_{1} t}
$$

Substituting (6) into (3) yields the following linear first order differential equation:

$$
\frac{d B}{d t}+k_{2} B=k_{1} A_{0} e^{-k_{1} t}
$$

Since (7) is a linear first order differential equation it is well known the solution is of the form,

$$
B(t)=e^{-\int k_{2} d t}\left[\int\left(k_{1} A_{0} e^{-k_{1} t} e^{-\int k_{2} d t}\right) d t\right] .
$$

Performing the integration in (8) along with the initial condition $B(0)=0$ produces,

$$
B(t)=A_{0}\left(\frac{k_{1}}{k_{2}-k_{1}}\right)\left(e^{-k_{1} t}-e^{-k_{2} t}\right) .
$$

We used an Excel solver to find that the values

$$
A_{0}=245.8769, \quad k_{1}=0.109456, \quad \text { and } \quad k_{2}=0.017727
$$

minimize the Mean Absolute Error when the values from $B(t)$ are fitted with the experimental data given in Table 1 .

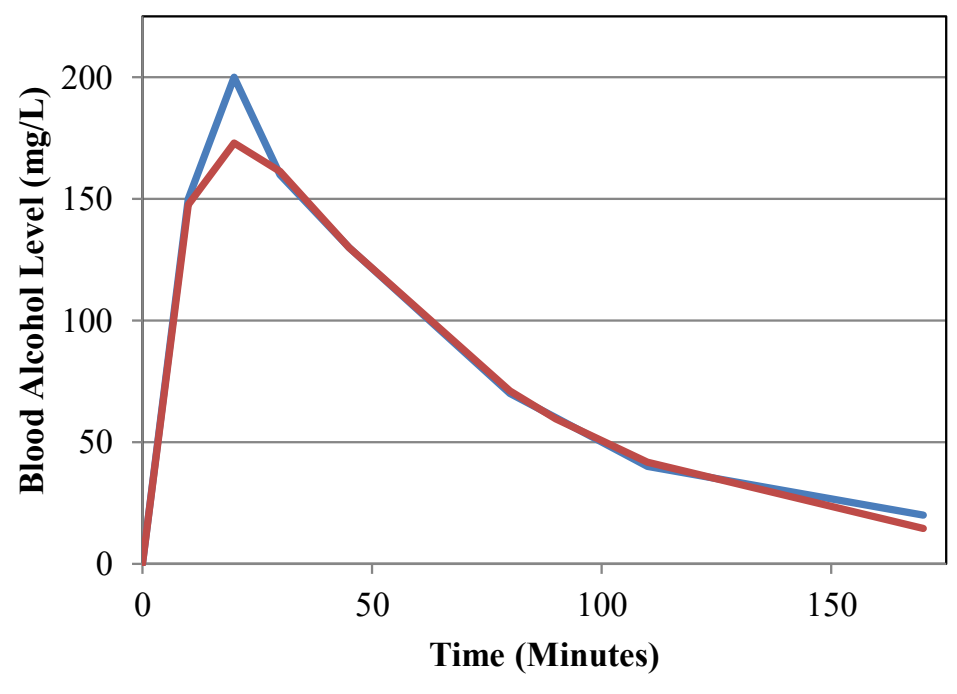

$\longrightarrow \mathrm{B}(\mathrm{t})$ : Experiment $\quad \longrightarrow \mathrm{B}(\mathrm{t}):$ Model

\begin{tabular}{|c|c|c|}
\hline \multirow{2}{*}{ Time } & \multicolumn{2}{|c|}{ Blood Alcohol Level } \\
\cline { 2 - 3 } & Experiment & Model \\
\hline 0 & 0 & 0.00 \\
\hline 10 & 150 & 147.54 \\
\hline 20 & 200 & 172.95 \\
\hline 30 & 160 & 161.38 \\
\hline 45 & 130 & 129.99 \\
\hline 80 & 70 & 70.99 \\
\hline 90 & 60 & 59.49 \\
\hline 110 & 40 & 41.74 \\
\hline 170 & 20 & 14.41 \\
\hline
\end{tabular}

Table 2: Plot of blood alcohol level for subject versus theoretical model with best fit parameters $A_{0}$, $k_{1}$, and $k_{2}$. 


\section{DISCUSSION}

The results from modeling equation (9) are illustrated in Table 2. Equation (9) was fitted to the data by minimizing the individual differences in calculated values versus experimental values. This was accomplished by using the solver tool in Microsoft Excel with the data seen in the above table. Excel produced the given values for the constants, and the average accuracy of the model was found to be $94.4 \%$.

This model turned out to be reasonably accurate at predicting the concentration at a given time, as is evidenced by the relatively close correlation of the data. Following the methods outlined within this report, it can be safely said that this is a reliable mathematical model for describing blood alcohol content. This implies that the metabolic pathway of ethanol is quite well described using simple first order kinetics. This represents a mildly surprising example of how a seemingly complicated system such as a biological one can be broken down into smaller parts and approximated with mathematical models.

At the same time, this experiment also has potential flaws in its ability to make predictions, and thus in its usefulness. The constants obtained through the data are not going to be the same for any two subjects, they are going to vary based on weight, size of subject's stomach, quantity of blood in subject's system, liver function of said subject, and many other potential variables. As such, this technique represents a good method for interpolating information from given experimental data, but further research must be done to test its reliability for a general population.

\section{CONCLUSION AND RECOMMENDATIONS}

The project's key objectives were to come up with a mathematical model that could be fitted to the proposed metabolic pathway scheme for ethanol. The aim was to evaluate this 
proposed method as a technique of modeling blood alcohol level as a function of time. Initially, two differential equations based upon concepts of first order chemical rate equations were given. The two governing equations were manipulated and combined using the separation of variables and integration techniques to produce a relationship that models the blood alcohol level of a subject as a function of time. By fitting this equation to the given experimental data for a specific subject, the constants in the equation were resolved. The respective accuracy level of each of the individual data points were then averaged together to quantify the overall percent accuracy of the model. The results suggest that the model predicted the experimental values with an average accuracy of $94.4 \%$. Given the relatively high accuracy of the calculated values, it can safely be said that the model was successful in describing the endogenous blood alcohol level of the subject.

However, if this data were to be used in some sort of medical environment, it would likely be beneficial to know the peak plasma concentration with higher accuracy. As such, it might be possible to produce a better approximation by breaking the time periods into different functions, such as modeling the period before peak plasma concentration separately to the period after, so that one function is increasing and the other decreasing. Additionally, there are also other parameters that could also be incorporated into the method to increase the accuracy, such as factors specific to a given subject like weight, quantity of blood in system, size of stomach, and other similar variables. Undoubtedly, a medical professional would take these things into account when assessing the implications behind the blood alcohol information. 


\section{NOMENCLATURE}

\begin{tabular}{|cll|}
\hline Symbol & Definition & Units \\
\hline $\boldsymbol{A}_{\mathbf{0}}$ & Initial concentration of alcohol in stomach & $\mathrm{mg} / \mathrm{L}$ \\
\hline $\boldsymbol{B}$ & Concentration of alcohol in blood & $\mathrm{mg} / \mathrm{L}$ \\
\hline $\boldsymbol{k}_{\mathbf{1}}$ & Rate law constant 1 & minute $^{-1}$ \\
\hline $\boldsymbol{k}_{\mathbf{2}}$ & Rate law constant 2 & minute $^{-1}$ \\
\hline $\boldsymbol{t}$ & Time & minute \\
\hline
\end{tabular}

\section{REFERENCES}

Larson, Ron, Robert Hostetler and Bruce Edwards. Calculus. 8th Edition. Boston, MA: Houghton Mifflin Company, 2005.

Connors, Kenneth A. Chemical Kinetics, the study of reaction rates in solution, 1991, VCH Publishers.

Stewart, James Essential Calculus- Early Transcendentals 2011, Brooks/Cole. 